\title{
SOBRE EL CONOCIMIENTO FÍSICO *
}

\section{Artículo primero. Estructura FORMAL de LA RELACión DE OBSERVABLIDAD}

1. Aceptemos como dato previo que los objetos de la ciencia física son dados en la observación. Se trata de un punto de partida; no discutiremos por ahora si, además, tal punto de partida es verdaderamente principio primero de que tenga, sin remedio, que partir la ciencia física. Y comenzamos por el estudio de la contextura formal o lógica de la relación de "observación".

Observación y observabilidad caen, ya a primera vista, bajo la categoría lógica de relación. $\mathrm{Y}$ de relación triargumental al menos; un cierto objeto(x) ostenta o manifiesta a otro(y) un cierto aspecto suyo(z). Que el color de un objeto negro sea observable (o esté siendo observado) implica que el objeto ostenta ante la vista precisamente el color, y no otras propiedades que pudiera tener.

Comenzamos por un simple punto de partida, que encierra una posibilidad de ser además principio; por esto nos basta con el concepto común, ordinario, vago de observación y observabilidad. Más adelante, y paso a paso, recibirá este concepto vago las debidas precisiones. Justamente porque partimos, y nos contentamos, con el concepto ordinario de observabilidad podemos estudiar su estructura formal: la de relación, sin complicarnos ya desde el comienzo en cuestiones de gnoseología, metafísica...

\section{Planteamiento lógico de la estructura de una relación}

2.1) Partimos de cinco axiomas referentes a la estructura de una relación, $R$, cualquiera.

\section{Axioma I}

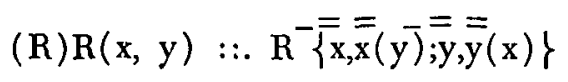

Es decir: si tenemos dos objetos cualesquiera, $\mathrm{x}, \mathrm{y}, \mathrm{y}$ los sometemos a una relación $R$, los objetos quedan descompuestos en dos componentes: $x$, en $\bar{x}, \bar{x}(\bar{y})$; e $y$, en $\bar{y}, \overline{\bar{y}}(\overline{\bar{x}})$; a saber, un aspecto o conjunto de aspectos que hacen de fundamento propio de dicha relación, aspectos que designamos con $\bar{x}, \bar{y} ; y$

- El autor ofrece a los lectores del Anuario Diánoia el primer capítulo de una obra: Teoría de las ciencias y filosofía de la ciencia, parte de la Metafísica especial, parte a su vez de la Metafísica general en curso de elaboración. En el próximo número de este Anuario habrá de publicarse el capítulo siguiente que versa sobre los Fenómenos y sus clases. 
otro aspecto o conjunto de aspectos que son los propiamente relacionales; designando con $\overline{\bar{x}}(\bar{y})$ lo que de $x$ entra en expresa relación con y; e $\bar{y}(\bar{x})$, lo que de y entra en relación explícita con $\mathrm{x}$.

Tomemos, por ejemplo, la relación de menor (mayor) entre 2 y 3. Es claro que no todos los componentes o notas que integran a 2 y a 3 entran propiamente en la relación de menor. Que 2 sea par y que 3 sea impar, que 2 y 3 sean primos absolutos, que 2 sea raíz cuadrada de 4 , que 2 y 3 sean números enteros... no son aspectos que propia e inmediatamente entren en la relación de menor; el 2 no es menor que el 3 por ser par, o por ser solamente número..., aunque, ciertamente, todo ello hace de fundamento sin el cual el 2 no sería menor que el 3. Por igual motivo: que A sea padre de $B$, exige o incluye, además de la expresamente afirmada y considerada relación de paternidad, el que A y B sean hombres, que sean vivientes, que sean reales... Todo lo cual no interviene directa y propiamente en la relación de paternidad, aunque sea imprescindible, como fundamento, para que la relación de paternidad sea real o se verifique. Estos aspectos: hombre, viviente, real... par, número entero..., designados aquí con $\bar{x}, \bar{y}$, tienen carácter lógico de propiedad (o función univariable, y se designan de ordinario con símbolos como $f(x), g(x) \ldots)$.

En cambio: al considerar 2 y 3 desde el punto de vista de las relaciones igual, mayor, menor, pasa a primer plano tal aspecto: que 2 es menor que 3 , y no otra relación. Que A y B sean hombres (función proposicional de una variable) queda de fundamento de la relación de paternidad que es la propiamente considerada, dejando de lado otras, como la mayor en edad, más alto, etc.

Podemos, pues, decir — siempre dentro de los límites iniciales prefijados-: toda relación $\mathbf{R}$ que rija entre dos objetos, $\mathrm{x}, \mathrm{y}$, los descompone en dos partes: una de propiedades que hacen de fundamento de la relación, fundamento más o menos próximo; y otra, de aspectos propiamente relacionados. Convengamos que los cuatro puntos :: indiquen "equivale $a$ ", y el punto quinto ::. indique la dirección en que tomamos la equivalencia, dentro de las dos direcciones que tiene toda equivalencia según la lógica; y podremos escribir más detalladamente el axioma $I$.

\section{Axioma 1.1}

$$
\text { (R) R(x,y) ::. }\left\{\left(\operatorname{EP}^{\prime}\right) \mathbf{P}^{\prime}(\overline{\mathbf{x}}),\left(\operatorname{ER}^{\prime}\right) \mathbf{R}^{\prime}(\overline{\bar{x}}, \overline{\mathrm{y}}) ;\left(\operatorname{EP}^{\prime \prime}\right) \mathbf{P}^{\prime \prime}(\overline{\mathrm{y}}),\left(\operatorname{ER}^{\prime \prime}\right) \mathbf{R}^{\prime \prime}(\overline{\bar{x}}, \overline{\bar{y}})\right\}
$$

Ponemos explícitamente la petición o postulado de que para cada relación exista $(\mathrm{E})$ o se dé una propiedad $\mathrm{P}$, que haga de fundamento de la relación, y que tal propiedad se halle a su manera en cada uno de los tér- 
minos relacionados $\left(E P^{\prime}\right) \mathrm{P}^{\prime}(\bar{x}),\left(E P^{\prime \prime}\right) P^{\prime \prime}(\bar{y})$; las propiedades $\mathrm{P}^{\prime}, \mathrm{P}^{\prime \prime}$ podrán ser iguales, por ejemplo en el caso de la relación de semejanza en el mismo color; la propiedad es el color poseído por dos cuerpos, semejantes por ser los dos rojos, verdes...; o podrá ser distinta, vgr. 2 es menos que 3 , porque 2 tiene dos unidades, y 3 tres; ahora que "tener unidades" es una propiedad de cada uno de los números, base de que uno sea menor que otro (relación).

Por igual motivo: toda relación, impuesta efectivamente entre dos términos, incluye dos subrrelaciones, o toma en los términos dos formas: $\left(\mathrm{ER}^{\prime}\right) \mathrm{R}(\overline{\mathrm{x}}, \overline{\mathrm{y}}), \quad\left(\mathrm{ER}^{\prime \prime}\right) \mathrm{R}^{\prime \prime}(\overline{\bar{x}}, \overline{\bar{y}})$, directa e inversa; 2 es menor que 3 , $\left(\operatorname{ER}^{\prime}\right) R^{\prime}(x, y)$; y 3 es mayor que $2\left(\operatorname{ER}^{\prime \prime}\right) R^{\prime \prime}(x, y)$.

Es claro que se darán casos en que $R^{\prime}, R^{\prime \prime}$ sean la misma relación, como en las de igualdad, semejanza... y, en general, en las simétricas. Se corresponden, pues $\bar{x}$ con $\left(E P^{\prime}\right) P(\bar{x}) ; \bar{y}$ con $\left(E P^{\prime \prime}\right) P^{\prime \prime}(\bar{y}) ; \overline{\bar{x}}(\overline{\bar{y}})$ con $\left(E R^{\prime}\right) R^{\prime}(\overline{\bar{x}} \overline{\bar{y}})$; $\overline{\bar{y}}(\overline{\bar{x}})$ con $\left(\operatorname{ER}^{\prime \prime}\right) R^{\prime \prime}(\overline{\bar{x}}, \overline{\bar{y}})$. $\mathrm{Y}$ podremos emplear, según las conveniencias, una de las dos formas de expresión.

La aplicación de esta descomposición en propiedad y relación al caso físico de la relación general de observabilidad será objeto del artículo segundo de este trabajo.

El axioma I podría formularse de dos maneras: a) si nos consta que entre los objetos $x, y$ rige una relación $\mathrm{R}$, podremos concluir que tales objetos están descompuestos en dos partes: una proposicional y otra relacional, haciendo la primera de fundamento de la segunda. Y en rigor: en dos proposicionales y en dos relacionales. b) Si dados dos objetos intentamos imponer entre ellos una relación que de suyo no tienen, sabremos que tal relación se ha impuesto efectivamente si logramos descomponerlos en dos partes: una proposicional, otra relacional. Ejemplo: la relación " 2 menor que 3 " pertenece al primer caso; que " 2 sea menor que 3 " no lo imponemos nosotros; parece cual si rigiera necesariamente entre 2 y 3 , por ser tales números. En cambio: la relación de observación parece cual si nosotros la impusiéramos, haciendo mayor o menor violencia a lo real. Y sabremos que efectivamente la hemos impuesto si, por el método que sea, notamos que los términos de esta relación quedan descompuestos en dos partes (cuatro): proposicional y relacional. De ello hablaremos con el detenimiento debido inmediatamente. La forma $b$ ) es la propia de la física, y en general de la teoría del conocimiento real.

2.2) Añadamos un axioma más.

\section{Axioma II.}

Para toda relación ( $R$ ), se da una propiedad absoluta que vale de cualquiera (de todos) los términos de la relación. 


$$
\text { (R)R }(x, y):: \quad(x, y)(E \bar{P}) \bar{P}(/ w /) .
$$

Expliquemos el significado del axioma II. Si entre 2 y 3 rige la relación de menor que (mayor que), tanto para 2 como para 5 existe, al menos, una propiedad absoluta, es decir: que no entra en tal relación, por ejemplo, la propiedad de ser enteros, de ser números, de ser magnitudes, de ser entes... que vale de los dos $-2,3-$ y que es como un valor absoluto $/ \mathrm{w} /$, es decir: no relacional, de ambos. 2 es número, 2 es real, 2 es ser...

Si $R$ es la relación de paternidad $-\mathrm{A}$ es padre de $\mathrm{B}-$, se da al menos una propiedad absoluta, que no entra de suyo en la relación de paternidad, vgr. la de ser hombre, sustancia, ser, real... que conviene tanto a A como a $B$, y que es como un valor absoluto /w/ de A y de B.

Lo cual viene a decir que toda relación tiene, en última instancia, algo absoluto que no entra en ella; o que no se da un proceso al infinito en las relaciones; o que relación no se funda en relación, que relación de relación no se funda en relación...

Si por $R, R^{\prime}(R), R^{\prime \prime}\left(R^{\prime}\right)$.. designamos relaciones que se fundan unas en otras..., podemos afirmar, expresando el axioma II de otra manera:

$$
\mathrm{R}^{(\mathrm{n})}(\mathrm{R}): . . / \mathrm{W} / \quad, \mathrm{n} \text { finito. }
$$

(Donde el signo :.. indica una especie de implicación, más amplia que la ordinaria, y de que se hablará más adelante, al comparar los diversos tipos de implicación que iremos introduciendo.)

Dado un conjunto variado (Mannigfaltigkeit) de objetos - $-\mathrm{a}, \mathrm{b}, \mathrm{c}-$ tiene que darse una propiedad absoluta al menos, que convenga a todos ellos, a cada uno, para que pueda hablar de un conjunto, y no me encuentre ante cosas tan dispares, heterogéneas, inconexas, que no tenga sentido hablar de un total, todo, conjunto. Dos, hambre, justicia... no forman un conjunto si no se da un aspecto absoluto, es decir: que prescinda de la relación de diferencia, diversidad, inconexión que se da entre ellas, tomadas cada una en su originalidad, y que permita uniformarlas, aunque tal aspecto absoluto sea el simple de ser todas y cada una algo, algo designable, objeto...

Podríamos afinar el axioma II fijando el número de pasos relacionales o de relaciones que se dan, respecto de varios objetos, antes de llegar a una de tales propiedades absolutas. $\mathrm{E}$ inclusive introducir el concepto de paso al limite, para $n$ infinito. Con lo cual el axioma II diría:

Toda sucesión de relaciones que se apoyen entre sí $y$ en objetos, $x, y$, tiende, necesariamente, a un limite que no es ya relación, sino un cierto absoluto.

$$
\underset{\lim . \mathrm{n} \rightarrow \infty}{\mathrm{R}^{(\mathrm{n})}}(\mathrm{R}) \quad \ldots / \mathrm{W} /
$$

Para la fundamentación de la física no tendremos que dar sino uno o dos pasos relacionales, y se llegará a un absoluto; a una propiedad que no entra ya en la relación o relaciones (finitas en número) consideradas. 
Una indicación orientadora: la relación de observación, al estudio de la cual va ordenado todo lo que estamos diciendo, lleva a inobservables, es decir: a propiedades que ya no entran en la relación de observación, y lleva al cabo de dos o tres relaciones; tienen sentido físico la relación de observación, la de observación de observación, y probablemente con esta segunda potencia de relación llegaremos a un absoluto, no observable ya. La fijación de en qué paso justamente nos tropecemos con una propiedad absoluta, respecto de la relación de observación, o sea con un inobservable, caracteriza las diversas físicas, clásica, moderna.

- 2.3) Para disponer de un sistema de referencia ideológico al que referir la teoría de la observación necesitamos, además:

\section{Axioma III}

Para todo objeto $x$ se da, al menos, una propiedad privilegiada que le conviene a él y sólo a él.

Por la lógica simbólica ordinaria se conocen funciones descriptivas (Kennzeichungen, Descriptions) que, sin mencionar por su nombre al objeto, remiten a él por un conjunto tal de predicados que sólo convienen a él. Vgr. El Libertador (Bolívar), el Rey de Inglaterra, la mitad de 3, el doble de 4... Y se escribe esta función con ( $1 \mathrm{x}) \mathrm{f}(\mathrm{x})$; el único objeto $(\mathrm{x})$ que tiene la propiedad $f()$. La iota invertida ( 1 , operador iota) indica la frase el único objeto...

El axioma III invierte, de alguna manera, la teoría de las descripciones, afirmando que para todo objeto se da, al menos, una propiedad que le con. viene a él y sólo a él. Es el único que la posee. Por lo cual ponemos ante $\mathrm{P}$ el signo iota invertida.

$$
\text { (x) }\left(\mathrm{E}_{1} \mathrm{P}\right) \stackrel{\mathrm{P}}{ } \mathrm{P}(\mathrm{x})
$$

La propiedad privilegiada $\mathbf{P}$ que conviene a todo objeto, a cada uno, $y$ que no conviene a otro, por muy parecido o igual que sea, es, evidentemente, la de ser él. Si además tendrá otras que sólo le convengan a él, será cuestión diferente. Vgr. ser infinito (Dios); ser la única raíz positiva de $x^{2}-2=0$ $(+\sqrt{ } 2)$. Pero adviértase que estas frases han de tomarse en sentido inverso al normal: dado un objeto como Dios es preciso que tenga una propiedad que sólo le convenga a él y que si no la tiene no es él. No basta, pues, para que exista el que tenga propiedades comunes -genéricas, específicas... tantas cuantas queramos.

Pero como advierte la teoría de las descripciones, para que tales predicados propios de un objeto tengan sentido es preciso que, ante todo, conste por otra parte de la existencia del obieto correspondiente. No puedo hablar 
de la solución de una ecuación de primer grado, si no he demostrado antes que toda ecuación de primer grado tiene una solución, o que existe una solución. Suponiendo que exista, podré hablar de esta raíz. Ni de "El Libertador", si no sé por otras razones que Bolívar existió.

Además de las funciones descriptivas singulares, que se refieren a un solo objeto, como "el padre de Napoleón", "el Descubridor de América", "la raíz cuadrada positiva de 4", "el electrón que acaba de pasar por esta rendija...", se dan también funciones descriptivas plurales, que se refieren a un conjunto de objetos, conjunto que sea suficientemente uno para poder ser designado determinadamente. Vgr., el conjunto de las raíces de una ecuación de grado $\mathrm{n}^{\prime \prime}(\mathrm{n}>1)$; " $e l$ conjunto de los hijos de Noé", "el conjunto (o clase) de los divisores de 10", etc. Lo designado es, evidentemente, un plural que, con todo, forma una unidad perfectamente designable. Como dijimos anteriormente, para que tal función descriptiva plural tenga sentido es preciso que nos conste de antemano de que existen tales elementos. Suponiendo que haya demostrado con D'Alembert que toda ecuación algebraica de grado $\mathbf{n}$ con coeficientes enteros tiene tantas raíces (soluciones) como indica su grado $(\mathrm{n})$, podré hablar de el conjunto (clase) de raíces de la ecuación $x^{2}-1=0, x^{3}-2 x^{2}-5 x+$ $+6=0$, etc., aunque por de pronto no sepa señalar sus valores exactos.

La importancia para la física de este axioma salta a la vista. Permite dar sentido a las palabras éste, ése, aquél; este electrón, este lugar (aquí), este tiempo (ahora). O decir: el electrón que está aquí en este momento.

Entre la física clásica y la moderna habrá, entre otras, esta diferencia: que la física clásica emplea funciones descriptivas singulares, creyendo tener sentido físico comprobable, observable, las frases: este electrón, este fotón, esta partícula, el electrón que está aquí (en este lugar) ahora (en este tiempo); el cuerpo que estará en aquel tiempo en aquel lugar. . . Mientras que la física cuántica no atribuirá sentido físico sino a funciones descriptivas plurales: el conjunto (nube) de electrones que..., el conjunto de posiciones que puede tener tal electrón, el conjunto de cantidades de movimiento que puede tener tal partícula (según ciertos coeficientes o circunstancias); el conjunto de elementos que puede haber en tal celdilla energética, etc. Tales conjuntos son los designables físicamente, es decir, los observables. Y no los elementos sueltos.

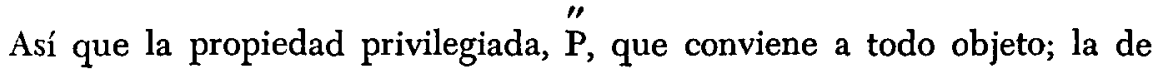
ser él, puede recibir estotra frase: éste, ése, aquél.

Pero a tenor de lo dicho habremos de distinguir dos formas del axioma: una referente a objetos sueltos; otra, a grupos de objetos (clases).

III.1 $(\mathrm{x})\left\{\left(\mathrm{E}_{1}{ }^{\prime \prime}\right) \stackrel{\mathrm{P}}{\prime \prime}(\mathrm{x})\right\}$, para un objeto suelto, cualquiera, $\mathrm{x}$.

III.2 $(\alpha)\left\{\left(\mathrm{E}_{1} \mathrm{P}\right) \mathrm{P}(\alpha)\right\}$, para un conjunto o clase, $\alpha$, de objetos. 
El axioma III, en sus dos formas, da sentido a la palabra éste.

2.4) Por motivos complementarios hace falta un cuarto axioma.

\section{Axioma IV}

Dado un objeto cualquiera, $x$, existe siempre una relación privilegiada que le conviene a él y sólo a él.

$$
(\mathrm{x})\left\{\left(\mathrm{E}_{1} \mathrm{R}\right) \mathrm{R}(\mathrm{x})\right\}
$$

La relación que conviene a cada objeto y sólo a él es, por de pronto, la de identidad, que es la que da sentido a la palabra: el mismo. Este electrón es el mismo que estaba hace un momento en..., hace tanto en..., hace tanto más en... Este cuerpo (vgr. el sol) es el mismo que ayer estaba en. .., ahora está en..., mañana a tal hora estará en..., etc. La relación de identidad es una función descriptiva singular o plural. El sistema solar es el mismo...; este volumen de gas es el mismo que antes estaba sometido a tal presión...

Una vez más entre la física clásica y la cuántica se interpondrá la diferencia: en la física clásica la relación el mismo puede aplicarse a objetos sueltos, o sea: la relación de identidad puede servir como función descriptiva singular, teniendo sentido físico, comprobable, hablar de este electrón que es el mismo que... Reforzar, pues, éste con el mismo. Mientras que la física cuántica no admitirá que el mismo tenga siempre sentido comprobable u observable aplicado a objetos sueltos, sean los que fueren, sino tan sólo, o preferentemente, a conjuntos de objetos: esta nube electrónica es la misma que. .. ; esta nube de fotones es la misma que...

Escribamos, pues, las dos formas:
IV.I
(x) $(\mathrm{E} 7 \mathrm{R}) \mathrm{R}(\mathrm{x}) \quad, \quad$ IV.2
$(\alpha)\left(E_{1} R\right) R(\alpha)$.

No hace falta insistir en que la relación "el mismo" refuerza la exigencia de observabilidad, de designabilidad de un objeto -exigencia natural y básica en una ciencia como la física.

2.5) Dada una relación cualquiera (R), que valga de los objetos $x, y$, tiene que darse $(E)$ otra relación privilegiada, $\bar{R}$, que vale a su vez de los valores absolutos de $x, y: / x /, / y /$.

Expliquemos, ante todo, el significado y alcance de este axioma. Por el axioma II sabemos que los términos de una relación tienen que tener, al menos, una propiedad absoluta que vale por igual de todos ellos, propiedad que no entra o hace de fundamento de la relación que se esté considerando. Ahora añadimos un paso más: cada uno de los términos de una relación tiene como valor absoluto esa misma propiedad absoluta. El valor absoluto de 2 es ser número, pues simplemente por ser 2 número no es menor que 3, 
que es tan número como él. Y si Pedro es padre de Pablo, el valor absoluto de los dos es el mismo: el de ser tan hombre uno como otro, de modo que sobre tal predicado o propiedad no puede establecerse la relación de paternidad y filiación. Pedro será padre de Pablo, precisamente en la proporción o medida o momento en que Pablo no era hombre y tenía que llegar a ser hombre. Así que los símbolos $/ \mathrm{x} /, \mathrm{y} /$ son abreviación de

$$
\overline{\mathrm{P}}(/ \mathrm{x} /), \overline{\mathrm{P}}(/ \mathrm{y} /) \text {. }
$$

El axioma IV nos dice: entre esos valores absolutos de $x, y$, se da, al menos, una relación privilegiada que es la de pertinencia, comparabilidad, coherencia, por la que dichos elementos constituyen un todo.

Así en virtud de la propiedad absoluta de ser A y B hombres, resultan comparables entre sí; puedo decir que son dos; que son de la misma especie... No nos hace falta, por el momento, afinar más el contenido de los términos: coherencia, pertinencia, comparabilidad.

Y escribamos el axioma V.

$$
(\mathbf{R}) \mathbf{R}(\mathrm{x}, \mathrm{y}):: \quad(E \overline{\mathrm{R}}) \overline{\mathrm{R}}(/ \mathrm{x} /, \mathrm{g} / \mathrm{y} /
$$

Esta relación de copertenencia de los elementos a un todo, tiene las siguientes propiedades:

1) reflexiva, $\bar{R}(/ x /, / x /)$,

2) simétrica, $\overrightarrow{\mathbf{R}}(/ \mathrm{x} /, \mathrm{y} / \mathrm{y} /)$ es lo mismo que $\overline{\mathbf{R}}(/ \mathrm{y} /, \mathrm{x} / \mathrm{x} /)$,

3) transitiva, de $\overline{\mathbf{R}}(/ x /, / y /)$ y de $\overline{\mathbf{R}}(/ y /, / z /)$ se sigue $\bar{R}(/ x /, / z /)$.

$\mathrm{El}$ hombre $\mathrm{A}$ es hombre; si $\mathrm{A}$ es hombre y $\mathrm{B}$ es hombre, los dos son hombres; son hombres A y B, y son hombres B y A; si A es hombre y B es hombre; si B es hombre y $C$ es hombre, son hombres A y B, y son hombres A y C.

Lo cual equivale a considerar un predicado, como el de hombre, en forma de relación reflexiva, simétrica y transitiva. Pedro es hombre, y Pedro es de la misma especie (hombre) que Pablo. Al concebir un predicado como especie le damos estatuto de relación. 2 es número entero; y 2 es de la misma especie que 3, a saber: de la especie "número entero". $E$ inversamente: si nos dan el concepto relacional de especie (género) puedo obtener un concepto o predicado uniargumental. Si 2 es de la misma especie (entero) que 3 , luego 2 es entero; luego 3 es entero.

Lo cual es posible porque se trata de predicados que valen del valor absoluto de las variables. En cambio, conceptos como menor que no pueden trocarse en predicados simples. Si 2 es menor que 3, no puedo decir que 2 es menor. Y es que la relación de menor no es reflexiva ni simétrica, aunque sea transitiva.

Cuando llegue el momento de hacer aplicación efectiva de estas nociones 
y axiomas a los objetos físicos se verá que el paso de una relación reflexiva, simétrica y transitiva a concepto-predicado de cada objeto, de modo que dé una proposición perfecta, trae consecuencias tan importantes como la constitución de clases (todo) de objetos, base del tratamiento estadístico de los objetos físicos correspondientes.

Por otra parte: la posibilidad de medición, o de introducir el concepto de medida, se basa en este axioma, ya que es reducir los objetos a un concepto común o a la relación reflexiva, simétrica y transitiva de medir. A es igual a $A$, según la medida $M$; si $A$ es igual a $B$ según la medida $M, B$ es igual a $A$ según esa misma medida; si $A$ es igual a $B$ según la medida $M$, y $B$ es igual a $C$ según la medida $M$, se sigue que $A$ es igual a $C$ según la medida $M$. Quede este hilo suelto para el momento oportuno.

\section{Espectro de una relación}

Interpretemos la relación como operador. Dados dos objetos (clases de objetos), x,y, si los sometemos a la operación "relacionarlos" con R -vgr. imponerles la relación de observación, la de conocimiento en general; la de menor, paralelo, antes-después-, los objetos y la relación se descomponen en

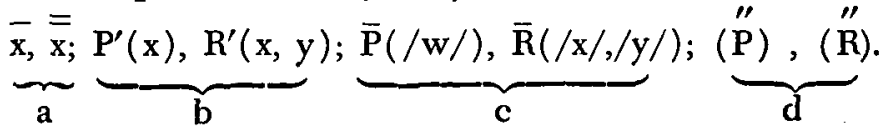

Y lo_mismo para $y$.

La importancia de esta descomposición que, por analogía, podemos denominar espectral, se echará de ver por sola esta advertencia: no todas las relaciones imponen a los objetos sometidos a ellas las ocho líneas o aspectos enumerados. El que una relación determinada imponga a los objetos a ella sometidos más o menos de tales líneas depende del estado en que se hallen objetos y relación. Hay relaciones degeneradas, como se dan en espectrografía líneas dobles, fundidas en una en ciertos estados. Una alusión más concreta aún: la relación de observación, de que nos vamos a ocupar inmediatamente, tiende a un límite en el que la relación de "observar", por parte del observador, no impone la descomposición de $x$ en $\bar{x}, \bar{x}$, ni la de $y$ en $\bar{y}, \bar{y}$. Lo cual expresa en forma definida y explícita lo que la física clásica, y la teoría del conocimiento en ella implicada y actuante, suponía: que el conocedor, por sólo ser conocedor, no es influído realmente por lo conocido. Que cabe un conocedor perfecto. $\mathrm{Y}$ a la vez un conocido perfecto, es decir: que un objeto por ser conocido no se resiente o descompone tampoco en los componentes indicados, $\bar{x}, \bar{x}$. Quedan $/ x /, / y /, y$ las líneas $b, c$, d. Se funden o comprenden las dos de (a); $\bar{x}, \overline{\bar{x}}$ en $/ x / ; \bar{y}, \bar{y}$ en $/ y /$. 
Respecto de los objetos matemáticos suele sostenerse la opinión de que la relación de conocimiento no hace nada en ellos. Que sus relaciones -menor, igual, mayor; doble, raíz; paralelo, congruente..., se hallan en los objetos matemáticos antes de todo acto de conocimiento, cual esencialmente vinculadas a ellos. Conocer un objeto matemático no implica hacer nada sobre él. Toda descomposición espectral en los ocho aspectos dichos se halla, de antemano y esencialmente, hecha en los objetos.

Todo lo cual, sea verdadero o falso, punto que por ahora no discutimos, supone una teoría especial del conocimiento: que el conocer es pasivo, ineficiente, y de otro orden que lo real, sin posible influencia directa sobre él.

\section{Artículo segrondo. De La estructura cONCRETA DE LA RELActón DE OBSERVACTóN}

\section{Observación y conocimiento}

Hasta este momento hemos dado por sabido qué se entienda por la relación de observación, y por la operación de Observar. Nos ha bastado el concepto previo vulgar, En el número presente presupondremos el concepto vulgar, corriente u ordinario (alltaeglich, Heidegger) de conocer, que, haciendo de concepto-fondo, nos permitirá precisar más delicadamente qué deba entenderse por observación.

Así que observación es, por lo pronto, una especial manera de conocimiento; una especie del conocer, cuya especificidad vamos. a aclarar, dejando con su claridad vaga eso de conocer.

\section{Caracteres del conocimiento observacional}

Dadas las cosas, el establecimiento o imposición de la relación de conocimiento las transforma en objetos (cosas conocidas). Hasta qué punto objeto transforme la cosa, será punto que aclararemos conforme lo exija la exposición. Pero suponer, ya desde el comienzo, como algo evidente que cosa conocida es lo mismo que cosa, es un pre-juicio. Que tal transformación sea real o racional (de razón) será asunto a discutir. Por de pronto enfoquemos esta relación desde el esquema espectral del número 3 (art. 1).

Dadas las cosas $x, y$, el establecimiento de la relación especial de conocimiento (de x cosa, a x cosa conocida; de y cosa, a y cosa cognoscente), produce de suyo (real o racionalmente) las cuatro líneas de descomposición espectral. Sea C, símbolo de la imposición o establecimiento de la relación de conocer. Tendremos

A) $C(x, y)::\left(\mathrm{Cx}_{0}, \mathrm{y}_{\mathrm{s}}\right)$. Por el mero hecho de establecer entre las cosas $x, y$, la relación de conocer, la cosa $x$ se transforma en $x_{0}$ (cosa conocida $=$ 
objeto); y la cosa y se cambia en cosa conocedora, en ys (sujeto). Abreviemos $x_{0}$ en $0, y y_{s}$ en $s$.

Tendremos como espectro a que referimos:

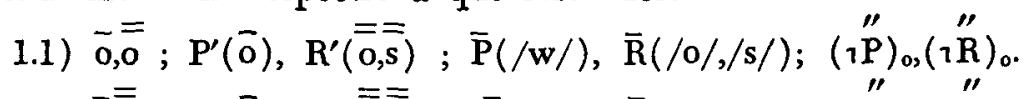

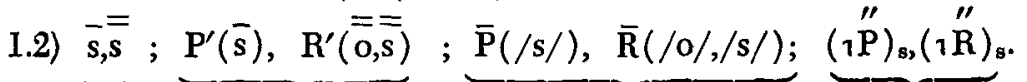

Según él caben los siguientes casos, como más interesantes en el momento presente, casi inicial, de nuestro trabajo:

1.11) Observación de hechos de primera clase $\left(\mathrm{H}_{1}\right)$.

El conocimiento puede intentar colocarse en estado tal que de 1.1) sólo

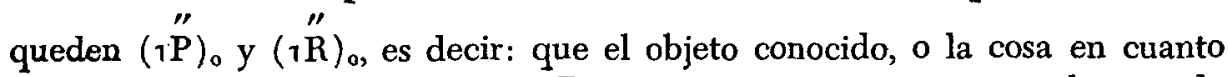
conocida, se me dé él y él mismo. De manera que crea que estoy observando este objeto justamente, éste y no otro, y además este mismo objeto. Un hecho de primera clase $\left(H_{1}\right)$ se definirá, según esto, por ser un objeto (electrón, protón, sol, Pedro...) dado como éste y este mismo. Para que tenga lugar tal tipo de conocimiento, es preciso que el conocedor quede reducido también a

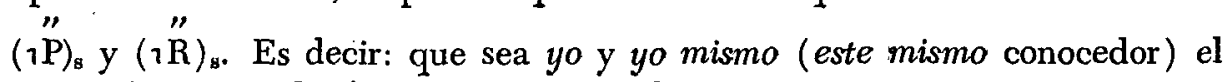
que esté conociendo éste y este mismo objeto.

El conacimiento de "este mismo" objeto exige que el conocedor se halle en estado de ser "este mismo" conocedor.

La relación de conocer se hallará entonces en estado de función descriptiva bisingular. Este mismo conocedor está conociendo este mismo objeto, y este mismo objeto está siendo conocido por este mismo conocedor. En rigor se tratará de una relación biunívoca bisingular.

Mas esta caracterización positiva implica otra negativa. Cuando soy yo, yo mismo, quien está conociendo este mismo objeto, la certeza o seguridad sujetiva del conocimiento parece ascender a su estado máximo.

Escribamos, pues, para disponer de una fórmula, cuyo uso estricto se acentuará en lo sucesivo,

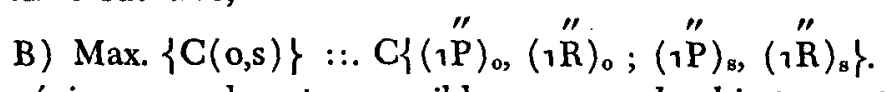

Si tal máximo es realmente asequible o no, queda abierto a estudio. Pero la exigencia de tal estado de máxima certeza, o de conocimiento biunívoco bisingular, trae como consecuencias: a) que el objeto conocido, por estar siendo conocido como éste y este mismo, no está presentando ninguno de los componentes (propiedad o relación) que le sean comunes con otros objetos; por tanto, $\mathrm{P}(/ \mathrm{w} /)$ y $\mathrm{R}(/ \mathrm{o} /)$ desaparecen del campo $\mathrm{u}$ horizonte del conocimiento biunívoco bisingular. Cuando hablo de este cuerpo, en cuanto éste, no puedo tomar eso de cuerpo en su aspecto común o genérico, sino decir: este cuerpo, que en cuanto este cuerpo lo está siendo de tan original y única manera 
(ésta) que no es sino de él... Y si de suyo, en otros tipos de conocimiento, puedo decir, y conocer, que Pedro es hombre, cuando se acentúe eso de Pedro, tendré que decir: Pedro es hombre, pero, en cuanto Pedro, Pedro es hombre de una manera singular y única; $y$, si no se pueden singularizar hombre o cuerpo..., tales aspectos no entrarán en $\mathrm{P}, \mathrm{R}$; en la función descriptiva singular. Lo cual equivale a decir que todo conocimiento que intente colocarse en plan de relación biunívoca bisingular no puede hacer uso de conceptos comunes, genéricos, específicos - ni de aparatos que valgan para uno-de-tantos, para un cualquiera. Cuando intento, por ejemplo, conocer que éste y este mismo electrón ha pasado por ésta y por esta misma rendija, que éste y este mismo electrón tiene ésta y esta misma posición..., me coloco en un especialísimo tipo de relación de conocer, o pongo el conocimiento en un estado singularísimo, que exige cuidadoso tratamiento de sus caracteres.

Primera reducción o degeneración de $\overline{\mathrm{P}}, \overrightarrow{\mathrm{R}}$, en componentes indeterminables.

Tenemos, pues, obtenida por examen de los presupuestos de teoría del conocimiento una primera fórmula del principio de indeterminación gnoseológica.

C) El conocimiento en estado biunivaco bisingular desconoce propiedades y relaciones comunes. $O$ no puede conocer simultáneamente propiedades $y$ relaciones comunes.

Tomemos 1 como operador; operador de singularizar: y designemos por C la relación inversa a conocer, a saber: no conocer, no poder observar, ocultar, precisamente por estar conociendo otro aspecto, y tendremos:

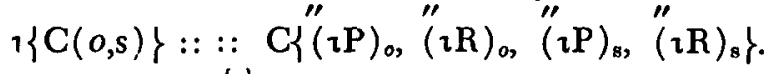

$$
\begin{aligned}
& \therefore: \stackrel{\mathrm{C}}{\mathrm{C}} \overline{\mathrm{P}}(/ \mathrm{w} /), \overline{\mathrm{R}}(/ o /, \ldots)\} \text {. }
\end{aligned}
$$

$\mathrm{Y}$ no se pierda ni un momento de vista que $\mathrm{C}$ es la inversa justamente de un C; quiero decir: que el ocultamiento particular de $\overline{\mathbf{P}}, \overline{\mathbf{R}}$ es resultante necesaria del descubrimiento (observación...) de P, R. Se trata, pues, de C y C complementarios. Y veremos más adelante que se les puede aplicar, con leve ampliación, el concepto matemático de conjugados. Lo son, en su sentido general más real, pues son descubrimiento-y-encubrimiento de componentes del mismo objeto, o, en rigor, de la misma cosa.

b) En este mismo electrón, en este mismo hombre (Platón, Aristóteles. . .), si recalco en lo de este mismo, no se puede señalar ninguna propiedad que haga de fundamento a la relación de conocimiento en estado de biunívoco y bisingular. Así que $\overline{\mathrm{P}}(/ \mathrm{w} /, \overline{\mathrm{R}}(/ \mathrm{o} / \ldots)$ quedan ocultados o son indetermina- 
bles. No sólo no puede servirme el que sean a y b electrones, para poder dar sentido a este electrón (a) y a este electrón (b), en cuanto éstos; ni cuerpo, ni electrón, pueden contribuir a explicarme eso de éste y de este mismo. Por tanto, no caben comparaciones de pertinencia, con las tres propiedades dichas. Y, de consiguiente, no tiene sentido una teoría del electrón, válida para todos, siendo cada uno uno de tantos, si intento aplicarla a éste, éste, éste... Pues de éste, éste, éste... no hay paso posible a todos. El Dos no es ni menor ni mayor ni igual que El Tres. Ni Platón es semejante o desemejante a Aristóteles, tomados ambos en su singularidad y su unicidad.

Platón es semejante a Aristóteles, tomados los dos en cuanto hombres, mas no lo son tomados los dos cada uno como lo que él es: Platón, Aristóteles. De consiguiente: la función 1 hace desaparecer, o vuelve incognoscibles (inexperimentales, inobservables) $\mathbf{P}^{\prime}(\overline{0}), \mathbf{R}^{\prime}(\overline{\overline{0}}, \ldots)$. No puede aparecer, pues, ninguna de las propiedades que hacen de fundamento de la relación -aquí la de observar; y tampoco puede aparecer ninguna de las relaciones que se asienten en el objeto en cuanto uno de tantos, semejante a, de igual peso que...

Hemos llegado a una segunda fórmula del principio de indeterminación en gnoseología.

D) El conocimiento, puesto en estado biunívoco bisingular, desconoce (oculta) las propiedades y relaciones que convengan al,objeto en ouanto uno de tantos. O sea: no es posible en tal estado conocer simultáneamente la propiedad y la relación original de "éste" y "mismo" junto con las propiedades y relaciones comunes entre tales objetos, reducidos al estrato de uno-de-tantos.

Empleando el simbolismo anterior:

$$
\begin{aligned}
1\{\mathrm{C}(o, \mathrm{~s})\} & :: \mathrm{C}\left\{(1 \mathrm{P})_{o},\left({ }_{1} \mathrm{R}\right)_{o} ;\left({ }_{1} \mathrm{P}\right)_{s},\left({ }_{1} \mathrm{R}\right)_{s}\right\} . \\
& : \therefore \mathrm{C}\left\{\mathrm{P}^{\prime}(\bar{o}), \mathrm{R}^{\prime}(\overline{\bar{u}}, \overline{\mathrm{s}})\right\} .
\end{aligned}
$$

(El subrayado, vgr. de las letras $o, s$ : indica a qué variable se aplica el operador $\tau$ ).

Nueva degeneración impuesta al espectro por el operador 1 .

Ahora podemos definir qué se entiende por Hecho de primera clase, $\mathrm{H}_{1}$.

Un hecho de primera clase es, por parte del objeto, lo dado a un conocimiento como éste y este mismo.

Así creemos que los hechos máximos son: esto que estoy yo viendo, en este lugar, en este momento, todo ello reforzado con este mismo. Estado del conocimiento en que no tanto insistimos en lugar, tiempo, masa, cuanto en éste y este mismo. Estado de intuición pura y perfecta.

Pero nos falta estudiar las modificaciones que en el conocedor introduce la exigencia de éste y este mismo (yo, yo mismo).

$\left.a^{\prime}\right)$ Consideremos el espectro relacional 1.2). 
Al ponerse el conocedor (observador, experimentador...) a conocer en cuanto yo y en cuanto yo mismo, deja de conocer necesariamente $\overline{\mathrm{P}}(/ \mathrm{s} /)$ y $\overrightarrow{\mathrm{R}}(\ldots, \mathrm{s} / \mathrm{s})$. Otro yo, y más aún, otro yo mismo, no lo hay; soy único ejemplar de una única edición posible. Por tanto, no formo universo con nadie ni nada. Mas al formar el valor absoluto del sujeto, $/ \mathrm{s} /$, no queda nada de yo ni de yo mismo. Claro que la frase "no quedar nada de" no hay que interpretarla por aniquilación, sino por no dejar residuo de sí en otro estado, cual metro cúbico de agua que pasó íntegramente a estado de vapor, sin residuo en estado líquido. Cuestión aparte es, evidentemente, si toda mi realidad, toda la del cognoscedor, puede ponerse o estar en estado de yo y de yo mismo. Por ejemplo: es dudoso que el yo empírico, el yo de todos los días, el yo masa, se puedan trocar o poner íntegramente en estado de yo transcendental (Kant), en que entra precisamente el estado de yo mismo (Selbst). Dejo este punto en alusión, pues su respuesta correcta presupone aún muchísimas otras respuestas.

$$
\begin{aligned}
& \mathfrak{1}\{\mathrm{C}(\mathrm{o}, s)\}:: \mathrm{C}\left\{(\mathrm{\imath} \stackrel{\mathrm{P}}{\mathrm{P}})_{0},(\mathrm{\imath} \stackrel{\mathrm{R}}{\mathrm{R}})_{0} ;(\stackrel{\mathrm{p}}{\mathrm{P}})_{8},(\mathrm{\imath} \mathrm{R})_{8}\right\} \text {. } \\
& \therefore \cup\langle\overline{\mathrm{r}} / \mathrm{w} /), \overline{\mathrm{R}}(\ldots / s /)\} \text {. }
\end{aligned}
$$

Cuando me dedico yo mismo a observar en plan intuitivo interno, dado íntegramente a notar que soy yo y yo mismo quien está notando, observando, experimentando tal o cual cosa, me sucede:

$\left.\mathrm{a}^{\prime \prime}\right)$ que no noto que yo sea hombre, como uno de tantos que hay, que yo sea cuerpo, como uno de tantísimos que hay..., de manera que tal valor absoluto me coloque en comunidad y comparabilidad con otros, dando todos, reducidos cada uno a uno de tantos, perdido el éste, un universo o un universal o conjunto. Yo no soy yo en cuanto hombre o cuerpo. Y yo mismo lo soy todavía menos en cuanto hombre o en cuanto cuerpo o en cuanto ser.

$\left.b^{\prime \prime}\right)$ Yo en cuanto yo, y yo mismo en cuanto mismo, no soy fundamento, por ser yo y yo mismo, de ninguna propiedad que sirva de fundamento a una relación. De modo que vale:

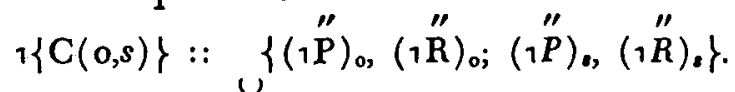

$$
\begin{aligned}
& \text { ::. } \mathrm{C}\left\{\left(\mathrm{P}^{\prime}(/ \mathrm{w} /), \mathrm{R}^{\prime}(\ldots / s /)\right\}\right. \text {. }
\end{aligned}
$$

Anulación $\mathrm{u}$ ocultamiento de toda clase de propiedades comunes o de relaciones entre sujetos, fundadas en lo que el yo tenga, en otro estado, de uno de tantos, de semejante a...

Pero todo esto, que es un dato inmediato de la conciencia, dado cuando nos empeñamos en notar explícitamente, justamente, que soy yo y yo mismo quien está viendo, oyendo, pensando..., tiene una ulterior consecuencia que no hallamos en el caso de aplicar al objeto conocido el operador éste y este mismo. A saber: $\mathrm{c}^{\prime \prime}$ ) al proponerme notar que soy yo y yo mismo quien está 
conociendo (viendo, observando...) desaparece de la conciencia en tal estado yoidal toda clase de objeto, no sólo lo que el conocedor tenga de parecido, igual, semejante a otros -en cuanto cuerpo, viviente...-, sino todo objeto externo, o lo conocido. Yo mismo, en cuanto yo mismo, no puedo conocer sino a mi mismo, -no puedo conocer cuerpo sino mi cuerpo, y en la medida en que tenga sentido eso de $m i$, aplicado a cuerpo; $m i$ alma, $m i$ acto de ver, $m i$ dolor, $m i$ color... Mi acto de pensar, en cuanto acto de $\mathrm{m}$ í mismo, notado como de mi mismo yo, puede dar tal vez carácter de mío a lo pensado, visto, oído..., y tiene que dárselo para que sea yo mismo, expresamente, realmente, el que esté pensando tal cosa, oyendo tal otra, viendo aquella... El acto de pensar un yo mismo exige que el acto sea mi pensamiento, de mí mismo, y que lo pensado sea de mí mismo, sea lo pensado por mí, por mi lo mismo; y, por tanto, lo pensado por un único, original, incomparable, desemejante a todos. Y en tal caso tal objeto pensado, visto, oído... por mi mismo, queda sustraído al universo, a los demás, a la ciencia. Un pensamiento que sea sólo mío no puede ser universal de cualquiera, en la medida en que sea realmente mío, de mí mismo.

De consiguiente: la exigencia de aplicar el operador iota al conocedor tiene doble efecto: a) hacer desaparecer del campo de lo conocido todo lo común, comparable, universal dentro del sujeto conocedor; b) desligar el objeto conocido de su incardinación, si la tenía, a un universo, de su carácter de universal y común aplicación, del orbe de la ciencia. Caemos, pues, en un sujetivismo solipsista. Lo cual no es, sin más, una refutación, sino una comprobación de sus consecuencias.

E) Nos hallamos, por tanto, ante una tercera forma del principio de indeterminación en gnoseología:

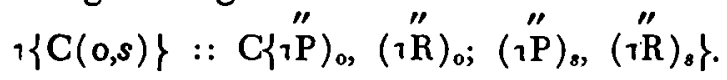

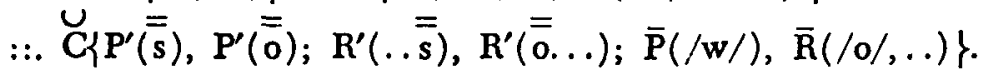

Desaparece, pues, la posibilidad de comparar lo que yo mismo estoy viendo con lo que pudieran ver los otros, o dicho de otro modo: saber si lo que yo mismo estoy viendo con un acto de mi mismo yo es lo mismo o parecido a lo que están viendo otros, ya que, por el estado en que me coloco no tiene sentido averiguar si hay otros que sean parecidos a mí, puesto que como yo no hay sino yo mismo, único.

Con todo, la exigencia de imponer el operador iota al sujeto conocedor tal vez pueda servir de método en psicología, en teoría del conocimiento transcendental, y para otros usos que no nos interesan en este momento.

Concluyamos:

F) Un hecho de primera clase $\left(\mathrm{H}_{1}\right)$ sería aquel en que el conocedor estuviera en estado de este mismo (yo mismo) y el objeto en estado de este mismo objeto que está siendo objeto de este acto de este mismo yo. Tipo de 
conacimiento biunívaco y bisingular. Tales hechos, si es que se dan, desincardinan al conocedor y a lo conocido del universo público, universal, científico.

1. 12) Hechos de segunda clase, $\mathrm{H}_{2}$.

Según el axioma V, dada una relación $R$, entre dos cosas, $x, y$, se da una relación $\overline{\mathrm{R}}$ que rige entre los valores absolutos de $\mathrm{x}, \mathrm{y}: / \mathrm{x} /, / \mathrm{y} /$, con las tres propiedades de reflexividad, simetría y transitividad. Diremos que tales objetos son entonces comparables entre sí - parecidos, semejantes, iguales-, dejando para más adelante definir justamente estas relaciones en sus diferencias mutuas. $\mathrm{E}$ introduzcamos esta relación de comparabilidad como operador, $\sigma$. Operador sigma.

Decimos: si sometemos la relación de conocimiento (en especial la de observación) a la operación sigma tendremos:

$$
\begin{aligned}
& \sigma\{\mathrm{C}(0, s)\}:: \mathrm{C}\{\overline{\mathrm{P}}(/ \mathrm{o} /), \overline{\mathrm{P}} / \mathrm{s} /) ; \overline{\mathrm{R}}(/ \mathrm{o} / \mathrm{s} / \mathrm{s} /)\} \text {. }
\end{aligned}
$$

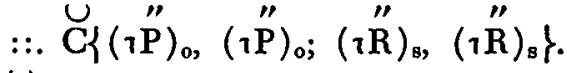

Complementaridad de $\mathrm{C}, \overleftrightarrow{\mathrm{C}}$, respecto de la operación sigma; complementaridad que proviene de la que rige entre las operaciones iota y sigma. Notemos lo que se obtiene por colocarse en este estado la relación de observar: $a^{\prime}$ ) el conocedor (por vista, oído, pensamiento...) es ahora uno de tantos (videntes, oyentes, pensantes...), del mismo orden, de modo que lo que él ve, oye, piensa..., por no estar afectado de la singularidad, de la función u operación "iota", vale exactamente igual de todos los demás (videntes, oyentes, pensantes, observadores...); según lo cual la objetividad de lo observado se consigue por no ponerse cada uno de los observadores en plan o estado de querer ser él y el mismo, en su originalidad y unicidad, el que observa. Es un dato que el observador puede colocarse en este estado de uno de tantos, sin insistir en que es él y precisamente él mismo quien está observando este objeto en cuanto este mismo objeto.

$b^{\prime}$ ) Por la parte de los objetos observados: el objeto observado no lo está siendo en cuanto éste y este mismo; sino en cuanto uno de tantos del mismo orden (uno de tantos electrones, uno de tantos protones...). No hay que confundir $-\mathrm{y}$ será punto a estudiar detenidamente más adelante-, observar uno o dos o más objetos, cada uno de los cuales es uno de tantos, con observar éste, estos dos. Puedo notar que por un cierto contador ha pasado un electrón, pero no este electrón; el uno que ha pasado es uno de tantos, sin individualidad perfecta, sin etiqueta que me permita físicamente seguirlo como este mismo. En caso contrario, de ser este mismo y no otro el que ha pasado por el contador Geiger, no podría aplicar la estadística, por tratarse de caso singular, único posible.

Es también un dato básico de teoría del conocimiento físico que el co. nocimiento conoce uno de tantos, mas no éste y menos este mismo. 
En un hecho de segunda clase, $\mathrm{H}_{2}$, uno de tantos objetos de un orden (molecular, atómico, cuántico...) es dado a uno de tantos observadores. La operación que pone en estado de uno de tantos a observador y a objeto es la operación "sigma".

Más adelante estudiaremos qué efectos observables trae consigo la pretensión que puede proponerse un observador consciente (el hombre, en cuanto éste y este mismo, en cuanto Platón, Planck...) de ser él mismo, quien esté observando este mismo objeto. El determinismo en física encierra, entre otras condiciones, el que sea uno mismo quien esté observando este mismo objeto, comprobando su mismidad. $\mathrm{c}^{\prime}$ ) De lo cual se sigue, como particular aplicación, que si el conocedor (observador...) toma su cuerpo como uno de tantos cuerpos, su posición en el lugar como una de tantas posiciones en el lugar, su duración o tiempo como uno de tantos tiempos..., podrá conocer un cuerpo como uno de tantos cuerpos, una posición de un cuerpo como una de tantas posiciones, una duración o sucesión de un fenómeno como una de tantas duraciones... Y esto: uno de tantos equivale a una fórmuda básica de relatividad. Lo que vale para este objeto que tengo delante vale para todos por ser éste uno de tantos. Así veremos qué sentido tiene uno de tantos sistemas de referencia, uno de tantos lugares que puede ocupar un cuerpo que es uno de tantos, etc.

Reduzcamos lo dicho a una fórmula: al aplicar a un objeto o conocedor la operación "sigma", se introduce una relatividad, o la falta de preferencia por un objeto como el único privilegiado, como este mismo. El centro del mundo, este mismo objeto que es el centro del mundo; este sistema de referencia, designable como este mismo, único, etc., quedan eliminados como imposibles de conocer.

Pero para tal estado de relatividad hace falta que tanto observador como observado estén o se pongan en estado de uno de tantos. Lo cual es, en principio, posible, por el axioma $\mathrm{V}$.

Conocedor y conocido están en el mismo nivel: uno de tantos. Esta unidad de estado hace que observador y observado concuerden entre sí; y concordancia entre conocedor y conocido ha sido, desde siempre, la definición de Verdad. La verdad física es posible porque conocedor y conocido pueden colocarse (o están colocados) en el mismo estado: precisamente el de uno de tantos.

\subsection{3) Hechos de tercera clase, $\mathrm{H}^{3}$}

Por el axioma $I$, si entre dos objetos $\mathrm{x}, \mathrm{y}$, se establece una relación, $\mathrm{R}$, los objetos quedan descompuestos en $\overline{\mathrm{x}}, \overline{\mathrm{x}}(\overline{\overline{\mathrm{y}}})$, e $\overline{\mathrm{y}}, \overline{\bar{y}}(\overline{\bar{x}})$; abreviadamente. $\overline{\mathbf{x}}, \overline{\bar{x}} ; \overline{\mathrm{y}}, \overline{\bar{y}}$ : Lo cual equivale a pedir que toda relación sea una operación real, que hace o ha hecho algo muy determinado en los sujetos en que se funda. Que, vgr., si entre 2 y 3 rige la relación de menor, $2<3$, tal relación ha he- 
cho en 2,3 , la descomposición $\bar{x}, \bar{x} ; \bar{y}, \bar{y}$. Es como imponer a una masa en reposo un movimiento, o un vector. Ya Aristóteles señalaba como efecto pro-

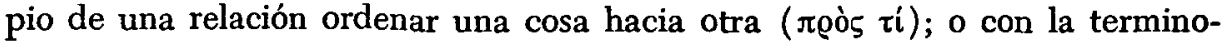
logía medieval, introducir un esse ad (ser hacia). Y en la física se hace intervenir la dirección y el sentido (vector). Y dirección y sentido no son cosas físicas: una dirección o el sentido de un vector no se componen de átomos, moléculas; una dirección no pesa, ni se dilata por el calor... Es un real "ser hacia", versus aliud. Y la eficiencia de un vector se nota en la necesidad misma de introducir un cálculo que tenga dirección, sentido... De 2 menor que 3 podemos decir que, desde siempre, está el 2 dirigido hacia el 3, de esa manera peculiar que le da el "vector" aritmético: "menor que".

Pero en lo físico toda relación que sea realmente física, y no puramente mental, tiene que hacer un efecto parecido: dirigir efectivamente un objeto hacia otro; descomponer un objeto en dos componentes, frente al estado inicial en sí anterior al establecimiento de la relación. Que dos masas se atraigan, implica que esa relación de atracción que surge, cuando dándose una, adviene la otra, sea relación real. Lo cual impone, según el axioma I, la descomposición de tal objeto $x$, en $\bar{x}, \bar{x}(\bar{y}) ; y$ del otro, $y$, en $\bar{y}, \bar{y}(\bar{x})$.

De qué modo se note tal descomposición, trataremos más adelante. Pero por de pronto toda relación tiene que hacer tal descomposición, que variará, como es natural y previsible, según el tipo de objeto.

Apliquémoslo a la teoría de la observación. Para el físico clásico, guiado por una teoría especial (no formulada expresamente) del conocimiento, la relación entre conocedor y conocido se reducía a una pura relación ineficaz, irreal, no física. El conocedor, por ser y mientras lo está siendo, no se descompone en $\bar{y}, \bar{y}(\overline{\bar{x}})$; y el objeto conocido, por ser o estar siendo conocido, no se altera; no se descompone en $\bar{x}, \overline{\bar{x}}(\overline{\bar{y}})$. Conocer es una relación puramente de razón, no física. Y lo mismo pasa respecto de conocer mediante aparatos, instrumentos... Por lo cual "observar" no se cuenta entre las operaciones físicas. Su eficiencia física es nula. Realismo ingenuo. No decimos aún que sea falso. Lo único que afirmamos es que, en principio, toda relación posee eficiencia propia, definida por la descomposición formulada en el axioma $\mathbf{I}$.

En principio, pues, la imposición o establecimiento de la relación de observar descompondrá observador y observado en los dos componentes dichos. Designemos con @ (rho) la "operación" de establecer una relación, tendremos

$$
\varrho C\{x, y\}:: \quad \varrho[\bar{x}, \bar{x}(\bar{y}) ; \bar{y}, \bar{y}(\bar{x})] \text {. }
$$

En general, $\bar{x}$ es diferente de $\bar{y} ; y$ las funciones $\overline{\bar{x}}(\overline{\bar{y}}), \overline{\bar{y}}(\overline{\bar{x}})$ son también, en general, diferentes. 
Para la física clásica, guiada por una teoría realista ingenua del conocimiento, tendremos: $\overline{\mathrm{x}}:: \overline{\overline{\mathrm{x}}}(\overline{\overline{\mathrm{y}}}):: \mathrm{O} ; \overline{\mathrm{y}}:: \overline{\bar{y}}(\overline{\overline{\mathrm{x}}}):: \mathrm{O}$.

En tal caso nos hallaríamos ante datos perfectos: objeto conocido, tal cual es en sí, ya que la relación de ser conocido por (sentidos, aparatos...) no lo altera; y conocedor, tal cual es en sí, ya que la relación conocer a tampoco lo transforma.

Definimos, pues, dato: En un conocimiento de datos puros ni el conocedor ni lo conocido se alteran por la relación de conocer (conocer a, ser conocido por). Un dato es lo que presenta un objeto "en si" a un sujeto "en si" también.

Según las fórmulas anteriores, la física clásica se define en teoría del conocimiento por el resultado de las operaciones iota, sigma, rho.

Operación iota,

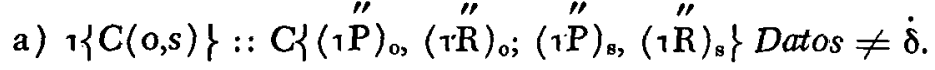

$$
\begin{aligned}
& \left\{\begin{array}{l}
\left.\mathrm{a}^{\prime}\right) \quad \mathrm{C}\left\{\mathrm{P}^{\prime}(\overline{\mathrm{s}}), \mathrm{P}^{\prime}(\overline{\mathrm{o}}) ; \mathrm{R}^{\prime}(\ldots, \overline{\bar{s}}), \mathrm{R}^{\prime}(\overline{\overline{\mathrm{o}}}, \ldots)\right\} \dot{=} \dot{\mathrm{O}} ; \\
\left.\mathrm{a}^{\prime \prime}\right) \quad \mathrm{C}\{\mathrm{P}(/ \mathrm{w} /), \mathrm{R}(/ \mathrm{o} / . .), \mathrm{R}(. . / \mathrm{s} /)\} \doteq \dot{\mathrm{O}} .
\end{array}\right.
\end{aligned}
$$

Operación sigma, b) $\sigma\{\mathrm{C}(\mathrm{o}, \mathrm{s})\} . \doteq \dot{\mathrm{O}}$.

Operación rho, c) $\quad \mathrm{Q}\{\mathrm{C}(\mathrm{o}, \mathrm{s})\} \doteq \dot{\mathrm{O}}$.

Las condiciones $a^{\prime}, a^{\prime \prime}, b$, c nos dicen que la física clásica no se funda en Hechos, sino en sólo Datos (a).

En contraposición, las ecuaciones simbólicas que definen la posición que en teoría del conocimiento adopta la física moderna (cuántica) son:

Operación iota A) $\quad\urcorner\{\mathrm{C}(\mathrm{o}, \mathrm{s})\} \doteq \dot{\mathrm{O}} . \quad$ Datos $=\dot{\mathrm{O}}$.

Operación sigma, B) $\sigma\{\mathrm{C}(o, \mathrm{~s})-\mathrm{C}(\mathrm{o}, s)\} \doteq \dot{\mathrm{O}}$. Relatividad.

Operación rho, C) $\mathrm{g}\{\mathrm{C}(\mathrm{o}, \mathrm{s})\} \quad \neq \dot{\mathrm{O}}$. Que se descompone en

c') $\overline{\bar{x}}(\overline{\bar{y}}) \div \overline{\mathrm{x}} \neq 0=\mathrm{k}^{\prime}$,

$\left.\mathrm{c}^{\prime \prime}\right) \overline{\bar{y}}(\overline{\bar{x}})-\overline{\mathrm{y}} \neq \mathrm{O} \doteq \mathrm{k}^{\prime \prime}$,

$\left.c^{\prime \prime \prime}\right) \overline{\bar{x}}(\overline{\bar{y}})-\overline{\bar{y}}(\overline{\bar{x}}) \neq 0 \doteq \mathbf{k}^{\prime \prime \prime}$.

B), C), y sus formas $c^{\prime}, c^{\prime \prime}, c^{\prime \prime \prime}$ definen la preferencia de la física cuántica por los Hechos. $\mathrm{A} \doteq \mathrm{O}$ indica su no admisión de datos.

La condición B) ha quedado caracterizada por la palabra Relatividad, que en forma negativa quiere decir la no existencia de un objeto privilegiado - este mismo (centro del mundo, sistema privilegiado de referencia, éter. ..). $\mathrm{Y}$ que tal diferencia sea nula indica que se hallan en el mismo nivel sujeto $(s)$ y objeto $(o)$; ambos son uno de tantos cuerpos, en uno de tantos lugares, en uno de tantos tiempos. 
Nótese que el signo - indica no precisamente una diferencia aritmética, sino diferencia en general; $y$ por igual motivo las constantes $O, k^{\prime}, k^{\prime \prime}, k^{\prime \prime \prime}$ indican o falta de diferencia $(\mathrm{O})$, o diferencias constantes, cual las que puede haber cualitativamente entre hombre y bruto, dos y cuatro... Veremos en qué momento y con qué condiciones se transforman tales diferencias, por de pronto cualitativas, en cuantitativas. Pero por ahora no nos hace falta más que diferencias cualitativas.

Artículo tercero. Definición gNoSEOLÓGica DE REALIDAd Física

1. Las operaciones estudiadas en el artículo anterior nos permiten fijar la definición de realidad física. Nos referimos, por de pronto, a realidad gnoseológica, es decir: a la realidad tal como está siendo dada al conocimiento.

Y para que algo, dado a la conciencia, lleve, por definición, el título de real pedimos:

a) que cumpla la función u operación sigma, es decir: que sea real para cualquiera, para todos y cada uno, en cuanto que cada uno es uno de tantos; $\mathrm{y}$, de consiguiente, no atribuiremos el título de real a lo que sea tan singular, tan caso único, que resulte irreductible a todo lo demás; por parte del conocedor no consideraremos como acto de conocimiento real el conocimiento que tenga el carácter de éste y este mismo. Todo lo que conozca yo en cuanto yo mismo, dando a esta palabra la fuerza de la operación iota, queda excluído de la categoría de conocimiento físico. Y un objeto que se presente como éste y este mismo quedará por igual motivo excluído de objeto físico. Si para otras ramas de conocimiento tendrá importancia decisiva tal clase de conocimiento y de objeto, sometidos a operación iota, es tema aparte de que se hablará en su lugar.

Esta condición equivale a un postulado de objetividad, en el sentido de exclusión de sujeto individual en cuanto tal; o equivale a pedir en física un observador cualquiera; que lo que observa uno pueda en principio observarlo otro, por ser todos y cada uno uno-de-tantos, un cualquiera. Esta relatividad es evidentemente una base de objetividad. Otra forma de enunciarla sería afirmar que todo conocimiento físico es independiente de la singularidad (yo mismo, tú mismo) del observador, de un observador privilegiado; y por parte del objeto, que un objeto es real si es uno de tantos. La comparabilidad, tanto de los actos de un observador y observadores, cuanto de lo observado, exige que unos y otros sean uno-de-tantos.

b) Otro de los caracteres vagamente formulados que siempre se han pedido de un objeto o acto de conocimiento para que lleve el título de real es que el objeto sea en sí, y se mantenga en sí a pesar de su relación $a$ otro. Lo cual está implicado en la operación rho. Pues pedimos para un 
conocimiento real y para un objeto conocido real que la relación de conocer descomponga conocedor $y$ conocido en dos componentes, $\bar{x}, \bar{x}(\overline{\bar{y}}) ; \bar{y}, \bar{y}(\overline{\bar{x}})$. En que $\bar{x}, \bar{y}$ indican lo que el objeto guarda como en sí, en reacción contra la acción del conocedor que está transformándolo en objeto conocido, en algo para él; lo que se mide por $\overline{\bar{x}}(\overline{\bar{y}})$; y para que el conocedor sea real es preciso que guarde algo para en sí, a pesar de que el objeto, por ser objeto, atraiga hacia sí (intentio) al conocedor; $\overline{\bar{y}}(\overline{\bar{x}})$.

Si en un conocimiento y en un objeto conocido no se operara tal descomposición, el fenómeno del conocimiento no sería real. Tanto conocer como ser conocido dejarían a ambos, conocedor y objeto, en sí perfectamente, tan perfecta e íntegramente que no habría manera de notar que hubiese pasado nada real. El conocimiento surgiría porque sí, ya que el objeto no lo produciría; y la cosa conocida no quedaría alterada por su condición de ser objeto, pues ésta no haría nada real.

Ni conocer ni ser conocido importarían cambio alguno real. Caso de un paralelismo leibniziano perfecto.

Así que lo real queda definido por: a) lo que es en sí, a pesar de estar siendo para otro; b) lo válido para uno de tantos conocedores, suprasujetividad; c) lo que se presenta como uno de tantos objetos, en cuanto uno de tantos; supraindividualidad.

Caben, en un primer intento clasificatorio general, los casos siguientes:

1) que $\overline{\bar{x}}(\overline{\bar{y}})>\overline{\bar{y}}(\overline{\bar{x}})$, es decir: que el objeto conocido, en cuanto conocido, es más atraído por el sujeto conocedor que el conocedor, en cuanto conocedor, está siendo atraído o sacado de su en sí por el objeto. Y tal parece ser, sirva de ejemplo provisorio, el caso de una observación de objetos microscópicos mediante aparatos macrossópicos (conocedor-aparato), comparada con el caso clásico, en que el objeto conocido, en cuanto conocido, no es atraído realmente a la esfera del conocedor. Su para el conocedor, $\overline{\bar{x}}(\overline{\bar{y}})$, o bien es cero, o puede hacerse tan pequeño como se quiera. $\mathrm{Y}$ en tal concepción del conocimiento físico no habría inconveniente en que $\overline{\bar{y}}(\overline{\bar{x}})$ fuera diferente de cero, porque en física clásica lo que pasa en el conocedor, aun al conocer por aparatos, instrumentos, no entra en la esfera de lo físico. Queda confinado a la esfera puramente sujetiva. Todo lo cual podrá ser de hecho verdad, pero no nos consta por el examen de las condiciones generales del conocimiento real.

Es claro que, en el caso $\overline{\bar{x}}(\overline{\bar{y}})>\overline{\bar{y}}(\overline{\bar{x}})$, el objeto no parecerá tan real como en el contrario, a saber:

2) $\overline{\bar{x}}(\overline{\bar{y}}) \dot{\bar{y}}(\overline{\bar{x}})$ : el objeto es el centro preponderante, lo que parece 
estar siendo más en sí, para sí y menos "para otro". La observación de un objeto macroscópico por los sentidos - por ejemplo, el sol por los ojos-, correspondería, en una primera aproximación, a este caso, ya que no parece que el estar siendo visto, aunque sea por todos los ojos humanos de vez, altere en nada propiedad alguna del sol, o si lo hace es en magnitud tan pequeña que por ahora parece ser inobservable. Pero no hay que descartar semejante posibilidad. Pudiera ponerse a prueba si el estar mirando muchos ojos un objeto luminoso produce alguna alteración en algunas de sus propiedades -vgr., una especie de inercia, retraso de fase...-, lo que no sucedería, o no en igual grado que sometiendo el mismo objeto a una placa fotográfica. Dejemos, pues, tal posibilidad abierta teóricamente.

3) El caso $\overline{\bar{x}}(\overline{\bar{y}}) \doteq \overline{\bar{y}}(\overline{\bar{x}})$ indicaría que el en si o para sí de conocedor $\mathrm{y}$ conocido, y sus respectivos para el otro, son iguales, Relación de conocer simétrica. De este punto hablamos inmediatamente.

No perdamos de vista que los componentes $\overline{\mathrm{x}}, \overline{\bar{x}}(\overline{\bar{y}})$ e $\bar{y}, \overline{\bar{y}}(\overline{\bar{x}})$ lo son respectivamente de una misma realidad: del conocedor o de la cosa conocida. Más adelante introduciremos una operación especial: la de formar el valor absoluto de los dos componentes; lo que equivaldrá a una cierta reversión de conocedor y conocido al estado de cosas en sí. Lo cual exigirá que demos sentido comprobable, o al menos, inteligible a la reabsorción o reidentificación

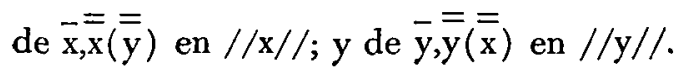

Tal operación, si es que tiene sentido real, permitiría responder a la cuestión: ¿qué son las cosas en sí cuando nadie las conoce de ninguna manera -ni con sentidos, ni con aparatos, instrumentos, mente?

Lo cual plantea el sentido de realidad óntica. Lo dejamos, por de pronto, de lado.

4) Si conocer el sujeto $s$ un objeto $o$, no es lo mismo que el que el objeto $o$ sea conocido por el sujeto $s, \overline{\overline{\mathrm{x}}}(\overline{\overline{\mathrm{y}}}) \neq \overline{\overline{\mathrm{y}}}(\overline{\overline{\mathrm{x}}})$, hemos de concluir que la relación de conocimiento no es simétrica, sino positivamente asimétrica. $\mathrm{C}(\mathrm{o}, \mathrm{s}) \neq$ $\neq \mathrm{C}(\mathrm{s}, \mathrm{o})$. El problema que se nos presenta en este caso es, probablemente, nuevo en teoría del conocimiento. Porque la relación de desigualdad es asimétrica, las relaciones parciales que la integran y explican, las de mayor-menor, se han como directa e inversa, y ambas son positivas. Si la relación de conocer, C, fuera perfectamente simétrica, o sea: $\overline{\bar{x}}(\overline{\bar{y}})=\overline{\bar{y}}(\overline{\bar{x}})$, podríamos concluir que no hay por qué distinguir entre conocedor y conocido; sus papeles serían intercambiables -como entre $a=b$, que pide $b=a$. $Y$, por tanto, tampoco habría motivo para distinguir entre $\bar{x}, \bar{y}$. Otra forma, clásica, de formular esta conclusión es sostener que el sujeto conocedor no hace nada en el objeto conocido, aun en el momento en que está siendo conocido; 
e inversamente, que una cosa, por darse a conocer, no hace nada real en el que la está conociendo. No hay forma más declarada de "idealismo" en teoría del conocimiento, es decir: de sostener el no realismo del conocimiento.

5) Si tomamos en serio, o sea como real, tanto el conocer como el ser conocido, el darse a conocer como el conocer, habremos de sacar otra consecuencia que, a su vez, nos proporcionará otra señal distintiva de realidad.

Si conocimiento es una relación real y eficiente (no decimos que esta su eficiencia sea por modo de causa, fuerza, etc.), tal relación tiene una directa y una inversa, ambas reales y eficientes. La relación de desigualdad tiene como directa e inversa las de mayor-menor; ambas positivas. Mas directa $e$ inversa están sujetas, por otra parte, a las relaciones cognoscitivas complementarias de anverso-reverso. Expliquémoslo: delante implica un detrás, antes un después, mayor un menor..., es decir: $R(x, y), U(y, x)$, que en general no son iguales, fuera del caso de relaciones simétricas. Mas si someto tales relaciones, directa e inversa -que, de suyo, son de vez, o a la una-, a la relación de conocimiento, una de ellas tiene que hacer de anverso y la otra de reverso. Cuando conozco precisamente que 2 es menor que 3 (anverso: lo que estoy mirando, lo que me está ofreciendo 2,3 ) no puedo estar conociendo, a la una, de vez, que 3 es mayor que 2 (reverso). Cuando veo de enfrente un cuerpo (anverso) no puedo verlo por detrás (reverso); la dirección hacia la derecha, mientras la sigo con la vista (anverso), oculta la dirección hacia la izquierda (reverso). Así que de la relación directa se pasa a la inversa por una inversión, que hace aparecer una de las dos relaciones, abstractamente o lógicamente complementarias, como anverso, y la otra como reverso. La forma como se me dé la relación anverso-reverso, cuál de las dos: directa o inversa, haga de anverso o reverso dependerá del tipo de relación considerada, de la intentio o dirección que tome el conocimiento.

Escribamos $R(x, y), \overleftrightarrow{R}(x, y)$ por directa e inversa, en que $\overleftrightarrow{R}(x, y)$ puede simbolizarse por $\mathrm{R}(\mathrm{y}, \mathrm{x})$; cada una de las dos admite un sentido doble, además de la dirección, $\mathrm{R}(\mathrm{x}, \mathrm{y}), \mathrm{R}(\mathrm{y}, \mathrm{x})$, a saber:

$\left.a^{\prime}\right)$ Si $A[R(x, y)], \overleftrightarrow{A}[R(y, x)]$; si $R(x, y)$ hace, respecto del conocedor (observador, experimentador...) de anverso - lo que no está ostentado o presentado hacia (versus) él一, la relación inversa, $R(y, x)$, tiene que hacer de reverso, de no conocida en primer plano, no enfrentada, no patente directa e inmediatamente. Tal no-patencia, no-ostentación directa o enfrente, es algo positivo, que podrá tomar la forma de profundo, fondo, base de lo que objeto ostenta en anverso.

$\left.b^{\prime}\right)$ Si $\left.\left.A[R(y, x))\right], \breve{A}[R x, y)\right]$; es decir: que si la relación inversa, $R(y, x)$ está haciendo de anverso - de lo considerado directamente, de lo visto por enfrente o delante...-, la relación directa, $R(x, y)$. pasa a segundo plano, 
a fondo, profundidad, no directamente considerado, visto, pensado. . . ; es decir, queda sometida a la relación real de reverso. Tanto anverso como reverso son algo positivo y especial para cada clase de relación, cuando se la somete, en sus componentes de directa e inversa, a la relación de conocimiento, de un conocimiento tomado en serio, en real.

La creación de un anverso y de un reverso es una de las eficiencias (no efectos, del tipo de los producidos por una causa, fuerza...) provenientes de someter algo a la relación de conocer.

Es claro que el necesario surgimiento de un reverso es una manera como el objeto conocido, aun mientras está siendo conocido, muestra que su realidad no es íntegramente absorbida por el conocedor, que no se trueca en contenido de su acto de conocer.

No tiene, pues, nada de misterioso el que ver un cuerpo produzca un reverso frente a lo visto (anverso) -eso que llamamos profundidad, fondo, y que es algo positivo, no algo meramente negativo. Es la reacción que la cosa opone a la acción absorbente del conocimiento, que, de suyo, intenta asimilar el objeto tanto como el estómago los alimentos: hacer de la cosa objeto íntegro, interno, al conocedor, algo sólo suyo, de él, de él mismo.

Por el mismo motivo: si darse una cosa a conocer implica descomponer al conocedor en dos componentes, $\overline{\mathrm{y}}, \overline{\bar{y}}(\overline{\bar{x}})$, a saber: un componente $\overline{\bar{x}}$, por el que la cosa cognoscente muestra que no es arrastrada integramente por el objeto que se le da a conocer $\longrightarrow$ que se le entra por los sentidos...-, y da la medida de lo que la cosa cognoscente guarda para ser en sí, a pesar de estar conociendo el objeto, es decir: de estar siendo para otro, $\overrightarrow{\bar{y}}(\overline{\bar{x}})$, tendremos que, en el conocimiento directo, en la actitud natural del conocer, el anverso lo constituye $\overline{\bar{y}}(\overline{\bar{x}})$, que es lo que del conocedor da hacia el objeto; mientras que $\bar{x}$ será lo que constituye el reverso; el fondo, el en sí del conocedor; lo que impide que se funda el conocedor con el objeto conocido, y no sepa el conocedor qué es lo que le ha pasado. Objetivación completa del conocedor. Cabe, como es claro, invertir la relación: darse a percibir el que uno está conociendo - anverso-; lo cual es atender al acto de conocer, a la conciencia, desatendiendo en grado menor o mayor a lo conocido, al objeto, que pasa entonces a fondo, vago y lejano, a reverso de tal dirección de reflexión del conocedor a sus propios actos. Introduzcamos, pues, además de la relación de conocer, anverso del $\mathrm{C}$, la relación de desconocer, reverso del $\mathrm{C}$. Sus símbolos son $\mathrm{c}$, c. $u$

Y decimos, como Axioma VI:

Axioma VI. El establecimiento de la relación de conocer, $C$, impone dos relaciones complementarias, un anverso de $C, c, y$ un reverso de $C, C$, tanto 
en la cosa conocida como en la cosa cognoscente. Anverso y reverso son invertibles.

Si la forma especial que toma el conocimiento es la de observación -que vamos definiendo por sus pasos-, la relación de reverso será la inobservabilidad, bien positiva, tanto como la de anverso, u observación. Todo lo observado implica o trueca en inobservable algo de la misma cosa observada, y de la observadora.

Hagamos una primera aplicación de estas ideas.

Si suponemos que a una cosa, $\mathrm{m}$, con dos características, $\mathrm{p}, \mathrm{q}$, se la somete a la relación de conocer (observar), tendremos la descomposición gnoseoIógica:

$$
\text { (1) } \mathrm{C}(\mathrm{m}):: \mathrm{c}\left(\mathrm{m}^{\prime}\right) \cdot \stackrel{\cup}{\mathrm{c}}\left(\mathrm{m}^{\prime \prime}\right) \text {. }
$$

$\mathrm{c}\left(\mathrm{m}^{\prime}\right)$ y $\mathrm{c}\left(\mathrm{m}^{\prime \prime}\right)$ no son dos trozos de la cosa $m$ que salgan disparados, separados, rotos; sino partes de la misma cosa que se mantiene en la misma o una, tanto al menos como lo son el reverso y anverso de una medalla, o la superficie y la profundidad de un objeto. Por eso ponemos el punto (.) que indique su unión o posición de vez.

Dejemos provisoriamente de lado lo que pasa en el conocedor, y concretémonos a lo que sucede a la cosa conocida.

$$
\text { (2) } c(p) \cdot c(q), \quad \text { (3) } c(q) \cdot c(p) \text {. }
$$

La observación de $p$ hace que la característica $q$ quede de reverso o inobservable; y la observación de $q$ hace que la $p$ queda de inobservable, de reverso. $\mathrm{p}$ y $\mathrm{q}$ se han, pues, como anverso y reverso, frente a la relación de conocimiento.

En el simbolismo empleado anteriormente

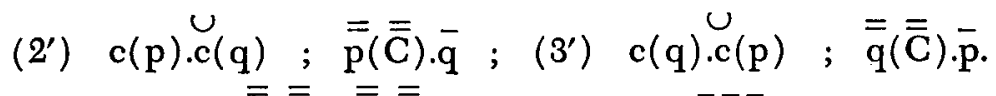

Que los anversos $\overline{\bar{p}}(\overline{\bar{C}}), \overline{\bar{q}}(\overline{\bar{C}})$, y los reversos $\bar{q}, \bar{p}$ sean iguales entre sí no es punto que podamos determinar sin más como necesario; en principio no lo serán. Dependerá, por de pronto, del conocedor (C), o de los medios que emplee (sentidos, aparatos, instrumentos, mente...).

Tendremos, pues, que, en principio,

$$
\text { (4) } c(p) \stackrel{u}{c}(q)-c(q) c(p) \stackrel{\cup}{=} k \neq 0
$$

Desde esta fórmula general, más bien cualitativa, hasta la forma cuantitativa concreta del principio de indeterminación de Heisenberg, faltan bastantes pasos que iremos dando por orden.

Resumiendo lo dicho en este artículo podemos fijar el sentido de realidad:

1) Lo que se mantiene en sí, precisamente durante su relación hacia otro; distinción simultánea entre $\bar{x}, \bar{x}(\overline{\bar{y}}) ; \bar{y}, \overline{\bar{y}}(\bar{x})$. 
2) Está mostrándose como real lo que está ofreciéndose como compuesto de anverso y reverso; anverso y reverso de la misma cosa.

3) Lo que se muestra como uno de tantos, uno cualquiera de su orden.

4) Lo que se muestra como uno de tantos conocedores. Caracteres de en sí, complementaridad, supraindividualidad, suprasujetividad.

Por donde se ve, entre otras cosas, que el principio de indeterminación, o de complementariedad entre observable e inobservable, es una muestra de la realidad del objeto que así se muestre.

\section{Casos-limite interesantes.}

a) Que el conocedor sea tan potente que reabsorba íntegramente la cosa conocida, por una especie de digestión cognoscitiva, parecida a la fisiológica. En tal caso lo visto, por ejemplo, terminaría siendo imaginado; lo oído, en sonido soñado... Lo real se transformaría en imagen, o en contenido de conciencia. En tal caso valdría la clásica fórmula de esse est percipi. La realidad de tales objetos consistiría en su ser percibido, en su estar siendo conocido. Si se da un tipo de conocimiento, $C_{1}$, tal que respecto de él todavía la cosa conocida mantenga sus dos componentes $\overline{\mathrm{x}}, \overline{\mathrm{x}}\left(\mathrm{C}_{1}\right)$, podría sobrevenir un tipo de conocedor más potente (vgr., el espíritu Absoluto, Dios, $\mathrm{C}_{2}$, tal que, al conocer $\left[\overline{\mathrm{x}}, \overline{\mathrm{x}}\left(\mathrm{C}_{1}\right)\right]$, lo transformara íntegramente en $\overline{\overline{\mathrm{x}}}\left(\mathrm{C}_{2}\right)$ en contenido de conciencia de $\mathrm{C}_{2}$, —n imagen suya, símbolo suyo, ...

Este caso-límite merece especial consideración, porque nos servirá para comparar diversos tipos de conocimiento físico que parecen apuntar hacia él. Una alusión a posteriores desarrollos: los sentidos (S), tal cual nos están dados, producen una composición de $x$, -en $\bar{x}, \bar{x}(S)$-, en que $\bar{x}$, está siendo más en sí que el $\bar{x}$ que le quedaría para ser en sí a la misma cosa si estuviera siendo conocida por un aparato (A); y la composición de la misma cosa respecto de un instrumento (I) disminuye aún más el $\bar{x}$, mientras aumentan en una cierta razón los componentes relacionales que vienen, metafóricamente, a expresar la atracción creciente de los tipos de conocedores, S,A,I.

$$
\begin{gathered}
\overline{\mathrm{x}}_{\mathrm{B}}>\overline{\mathrm{x}}_{\mathrm{a}}>\overline{\mathrm{x}}_{1} \ldots \\
\overline{\overline{\mathrm{x}}}(\mathrm{S})<\overline{\overline{\mathrm{x}}}(\mathrm{A})<\overline{\overline{\mathrm{x}}}(\mathrm{I}) \ldots
\end{gathered}
$$

En este proceso de comprobable interiorización del objeto conocido, o de reabsorción (Aufhebung) de las cosas en el conocedor, ¿podrá llegarse al límite indicado, en que $\overrightarrow{\mathrm{x}}$ sea igual a cero?

b) Cabe investigar el caso opuesto. En que la composición que el objeto introduce en el sujeto conocedor, la atracción del objeto sobre el sujeto, 
vaya creciendo, de modo que el en si del sujeto vaya disminuyendo, y creciendo su para el objeto.

Lo cual supondría la realidad de una serie de objetos desujetivantes en creciente potencia —casos de encandilamiento, obsesión... Sean tales objetos $\mathrm{O}_{1}, \mathrm{O}_{2}, \mathrm{O}_{3} \ldots$ con crecientes potencias de exteriorización del sujeto, de ponerlo fuera de sí. (ausser sich, Hegel); tendríamos con el simbolismo anterior:

$$
\begin{gathered}
\overline{\mathrm{s}}_{\mathrm{o}_{1}}>\overline{\mathrm{s}}_{\mathrm{o}_{2}}>\overline{\mathrm{s}}_{\mathrm{o}_{3}} \ldots \\
\overline{\mathrm{s}}\left(\mathrm{O}_{1}\right)<\overline{\overline{\mathrm{s}}}\left(\mathrm{O}_{2}\right)<\overline{\overline{\mathrm{s}}}\left(\mathrm{O}_{3}\right) .
\end{gathered}
$$

En el límite desaparecería del universo toda clase de conocedor; la conciencia, el en sí y para sí del sujeto.

Quede todo esto en forma de sugerencia, para cuyo plenario estudio nos faltan aún muchos elementos de juicio.

Universidad de Caracas, Venezuela.

Juan David García Bacca 